\title{
Synthesis and Characteristics of Multi-walled Carbon Nanotubes Coated Nanostructure TiO2
}

\author{
Jingheng Deng, Kanping Yu, Jianguo Xie, \\ Changsha Research Institute of Mining and Metallurgy, Changsha 410012, PR China
}

Keywords: anatase, nanostructure, $\mathrm{TiO}_{2}$, carbon nanotubes

\begin{abstract}
Nanostructure anatase $\mathrm{TiO}_{2} /$ carbon nanotubes $\left(\mathrm{TiO}_{2} / \mathrm{CNTs}\right)$ were prepared by hydrothermal process using acid treated CNTs and titanium (IV) sulfate. The materials were characterized using X-ray powder diffraction (XRD), scanning electron microscopy (SEM), and Brunauer-Emmett-Teller (BET). The results showed that anatase nano- $\mathrm{TiO}_{2}$ grew on $\mathrm{CNTs}$ and the $\mathrm{TiO}_{2}$ nanoparticles had diameters in the range of 30-50 nm. It was a facile approach to grow anatase nano- $\mathrm{TiO}_{2}$.
\end{abstract}

\section{Introduction}

Heavy metals are widely found in the effluents from the metallurgy, mineral benefication processing, electroplating, painting and other industries. Because of their non-biodegradable, highly toxic and probably carcinogen, they can be easily transported to environment and may cause serious problems to our health[1]. Many technologies have focused on the efficient elimination of the heavy metals pollutants, such as chemical precipitation, adsorption, reverse osmosis, electrodialysis, ultrafiltration, and ion exchange[2-6]. Among these technologies, Adsorption is widely applied because this method is easy to handle, relatively low cost, and simply equipment[7]. The key of adsorption technology is to improve the adsorption capacity of adsorbent. The efficiency of adsorptive removal is determined mainly by the adsorption capacity, selectivity for specific compounds, and durability and regenerability of the adsorbents[8]. In recently, the developments of nanoscience science for heavy metal removal have received remarkable attention due to their special features. Various nanosized adsorbents such as zirconium phosphate, TiO2 nanotubes, nanozerovalent iron[9], maghemite and hematite nanoparticles[10, 11], nano MgO[7] have been used for the removal of these toxic metal ions.

During the last year $\mathrm{TiO} 2$ has attracted much interest as a photo-catalytic agent, gas sensor materials and catalyst support due to its natural abundance, nontoxicity, photostability, low-cost, physical and chemical stability, and unique electronic and optical properties[9, 12-14].In addition, $\mathrm{TiO} 2$ has been demonstrated as a high capacity adsorbent for As removal from copper smelting wastewater[15] and other metal such as $\mathrm{Se}(\mathrm{IV}), \mathrm{Cu}, \mathrm{Hg}, \mathrm{Pb}$ [16].

Carbon nanotubes (CNTs) have brought out huge activity in composites science due to their intriguing nanoscale, low density, high specific surface area, intrinsically superior mechanical properties and excellent electrical and thermal properties[17]. Many studies have reported the production and characterization of CNT-based hybrid composites [7, 18]. CNT-based hybrid composites exhibit eminently synergistic performance. The coupling of $\mathrm{TiO} 2$ with carbon nanotubes has been shown to provide a synergistic effect which can enhance the overall efficiency of a photocatalytic process. The composites of titanate nanotubes with carbon nanotubes demonstrate high adsorptive capacity for $\mathrm{Pb} 2+$ and $\mathrm{Cu} 2+$.

In this study, we utilized a hydrothermal method to synthesize carbon nanotubes coated nano TiO2. The effects of synthesis temperature and solution $\mathrm{pH}$ values on the TiO2/CNTs crystallization and TiO2loading amount were analyzed. In addition, the as-prepared composites were used to remove heavy metal ions. 


\section{Experimental section}

\subsection{Materials}

The as-produced CNTs (diameter, 30-50 nm; length, 20 $\mu \mathrm{m}$ ) were purchased from Chengdu Institute of Organic Chemicals, Chinese Academy of Science. Titanium (IV) sulfate and concentrated HNO3 were purchased from the Beijing Chemical Reagents Company. All the other chemicals were analytical grade and used in this study without an additional purification.

\subsection{Purification of CNTs}

As-received CNTs ( $4.0 \mathrm{~g}$ ) were dispersed in $200 \mathrm{~mL}$ acid mixture of concentrated sulphuric acid and nitric acid with a volume ratio of $3: 1$ and constantly stirred at $40{ }^{\circ} \mathrm{C}$ for $6 \mathrm{~h}$. After cooling to room temperature, the black suspension was filtered and washed with water until $\mathrm{pH}$ neutral, and then dried at $80{ }^{\circ} \mathrm{C}$ for $6 \mathrm{~h}$. The dried CNTs were milled into powder for use.

\subsection{Synthesis of CNTs coated TiO2}

CNTs coated TiO2 were fabricated using Titanium (IV) sulfate and CNTs as supporter in water by hydrothermal method. CNTs (3 g) were added to $300 \mathrm{~mL}$ ultrapure water and dispersed by ultrasonic wave $(50 \mathrm{~W})$ for $10 \mathrm{~min}$. A certain amount of Titanium (IV) sulfate was added in the suspensions and adjusted to the desired $\mathrm{pH}$ with $\mathrm{HCl} / \mathrm{NaOH}$. The suspension was poured into stainless steel autoclave and sealed. And then the autoclave was heated to $150{ }^{\circ} \mathrm{C}$ with the speed $5{ }^{\circ} \mathrm{C} / \mathrm{min}$ and retained the temperature for 2-4 h. The autoclave was naturally cooled in air. The precipitate was filtrated and washed with ultrapure water. Finally the resulting products were dried in vacuum oven at $80^{\circ} \mathrm{C}$ for $24 \mathrm{~h}$.

\subsection{Characterization of samples}

The morphology and structure of the samples were characterized using scanning electron microscopy (SEM) (JSM-6490LV, Japan) transmission electron microscopy (TEM) (JEM-2010, Japan), and high-resolution transmission electron microscopy (HRTEM) (JEM-2010, Japan), equipped with selected-area electron diffraction (SAED). The X-ray powder diffraction (XRD) was carried out on D8 ADVANCE (Germany, Cu Ka, $\lambda=0.15406 \mathrm{~nm}$ ). The textural properties of the solid adsorbent was measured in a Quantachrome Nova-1000 equipment by physisorption of N2 at the temperature $77 \mathrm{k}$.

\subsection{Adsorption measurement}

The adsorption properties of the prepared TiO2/CNT for heavy metal ions $\mathrm{Pb} 2+$ was measured in batch experiments. $200 \mathrm{~mL}$ of solution containing $50 \mathrm{mg} / \mathrm{L} \mathrm{Pb} 2+$ were adjusted to desired $\mathrm{pH}$ values in the range of 5 to 11 with $\mathrm{NaOH}$ and H2SO4. $0.10 \mathrm{~g}$ of TiO2/CNT was added to solution and stirred at room temperature for $30 \mathrm{~min}$. The suspension was filtered through a $0.45-\mu \mathrm{m}$ membrane filter for $\mathrm{Pb} 2+$ analysis. The concentrations of the studied heavy metal ions in aqueous phase were determined using inductively coupled plasma mass spectrometry (ICP-MS, Thermo Fisher X Series II ).

\section{Results and discussion}

\subsection{The effect of temperature on crystallization}

Fixing the volume ratio of CNTs/Titanium (IV) sulfate at 2:1 and holding reaction time for $2 \mathrm{~h}$, the effect of temperatures on the crystallization was explored. Fig. 1 displays XRD patterns of the purified CNTs and samples obtained at various temperatures. As seen from Fig. 1, the diffraction peaks at $2 \theta=26.0^{\circ}$ can be indexed to the $\left(\begin{array}{lll}0 & 0 & 2\end{array}\right)$ reflection of CNTs. It indicated acid-oxidation pretreatment of CNTs did not damage significantly the structure of CNTs. The low intensities below $120{ }^{\circ} \mathrm{C}$ explicated $\mathrm{TiO} 2$ poor crystalline. The samples exhibited diffraction peaks at $2 \theta$ values around $25.5^{\circ}, 37.8^{\circ}, 48.0^{\circ}, 54.1^{\circ}$, and $62.7^{\circ}$ when hydrothermal temperature above $120{ }^{\circ} \mathrm{C}$. This ascribed to $\mathrm{TiO} 2$ characteristic diffraction peaks and can be easily indexed as the body-centered tetragonal phase of TiO2 (PDF: 21-1271). The broad diffraction peaks indicated that the crystalline size of TiO2 particles was quite small. The average crystal size was 30-40 nm. It was noticeable that the intensities of diffraction peaks gradually increased with increasing hydrothermal 
temperature from 120 to $180{ }^{\circ} \mathrm{C}$. When hydrothermal reaction temperature was $180{ }^{\circ} \mathrm{C}(\mathrm{t}=30 \mathrm{~min})$, the $\mathrm{TiO} 2$ nanoparticles increased. Accordingly, the optimal temperature was $150{ }^{\circ} \mathrm{C}$ in the present system.

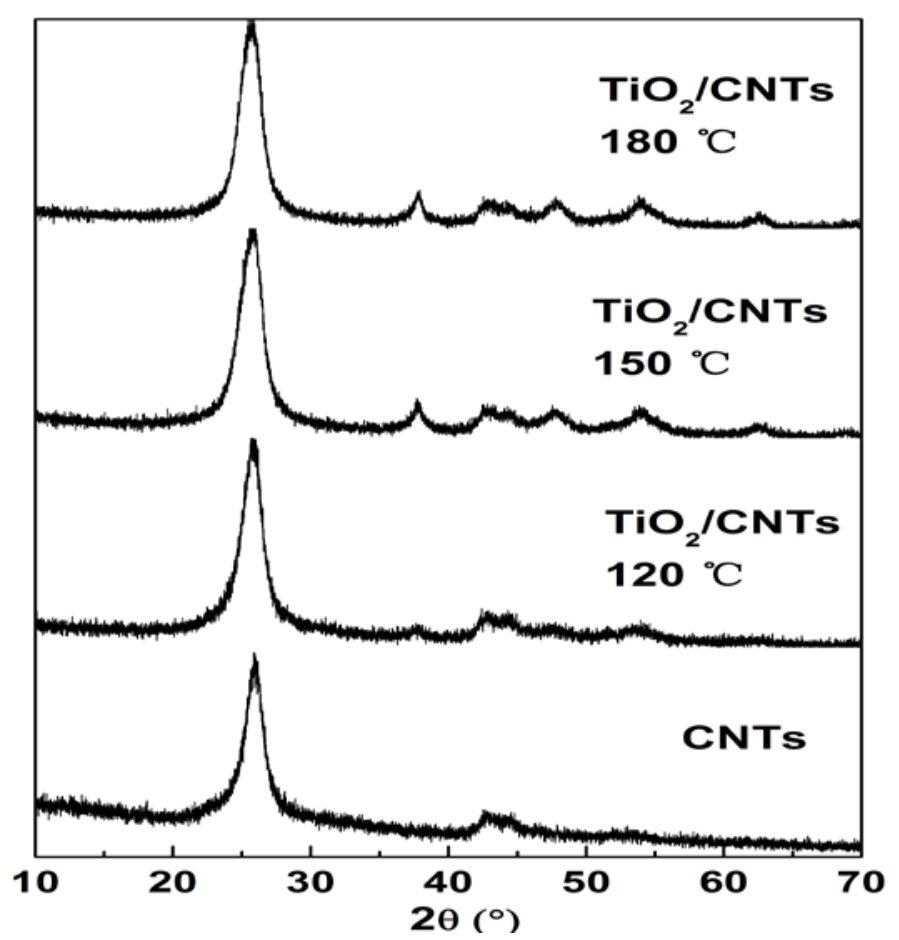

Fig. 1. The XRD patterns of purified CNTs and $\mathrm{TiO}_{2} / \mathrm{CNTs}$ prepared at various temperatures

\subsection{The effect of solution $\mathrm{pH}$ value on TiO2 loading amount}

The solution $\mathrm{pH}$ value influenced the TiO2 loadeing on the CNTs. Fig. 2 depicts the samples prepared at various $\mathrm{pH}$ values. The $\mathrm{TiO} 2$ nanoparticles aggregated when solution $\mathrm{pH}$ 3.0. While the solution $\mathrm{pH}$ increased to 9.8, the nanoparticles became small and the loading amount decreased. However, when the solution $\mathrm{pH}$ 12.1, the $\mathrm{TiO} 2$ nanoparticles were not loaded adequately. The $\mathrm{TiO} 2$ did not adhere to CNTs, but formed independently nanoparticles. Therefore, an increase in $\mathrm{pH}$ is unfavourable to the formation of TiO2/CNTs.

The formation of TiO2/CNTs hybrids involved basically two steps: Step 1) Titanium (IV) sulfate can hydrolyze easily to form H2TiO3. The reaction process probably involves the following chemical reactions:

$$
\begin{aligned}
& \mathrm{Ti}\left(\mathrm{SO}_{4}\right)_{2}+\mathrm{H}_{2} \mathrm{O}=\mathrm{TiOSO}_{4}+\mathrm{H}_{2} \mathrm{SO}_{4} \\
& \mathrm{TiOSO}_{4}+2 \mathrm{H}_{2} \mathrm{O}=\mathrm{H}_{2} \mathrm{TiO}_{3}+\mathrm{H}_{2} \mathrm{SO}_{4}
\end{aligned}
$$

Step 2) To some extent, the CNTs serves as a nuclei for TiO2 epitaxial growth via heterogeneous nucleation. Defects and organic groups on CNTs surface facilitate the binding of metal atoms.

The experiments demonstrated that the pHiep (isoelectric point) of oxidation CNTs is 2.1, and the absolute value of the zeta potential increased with the increased $\mathrm{pH}$ values. The surface potential of CNTs increases with increasing $\mathrm{pH}$ of the solution. The metatitanic acid radical is very difficulty to access CNTs due to electrostatic repulsion. Accordingly, the optimal $\mathrm{pH}$ value was 5 in the present system. 

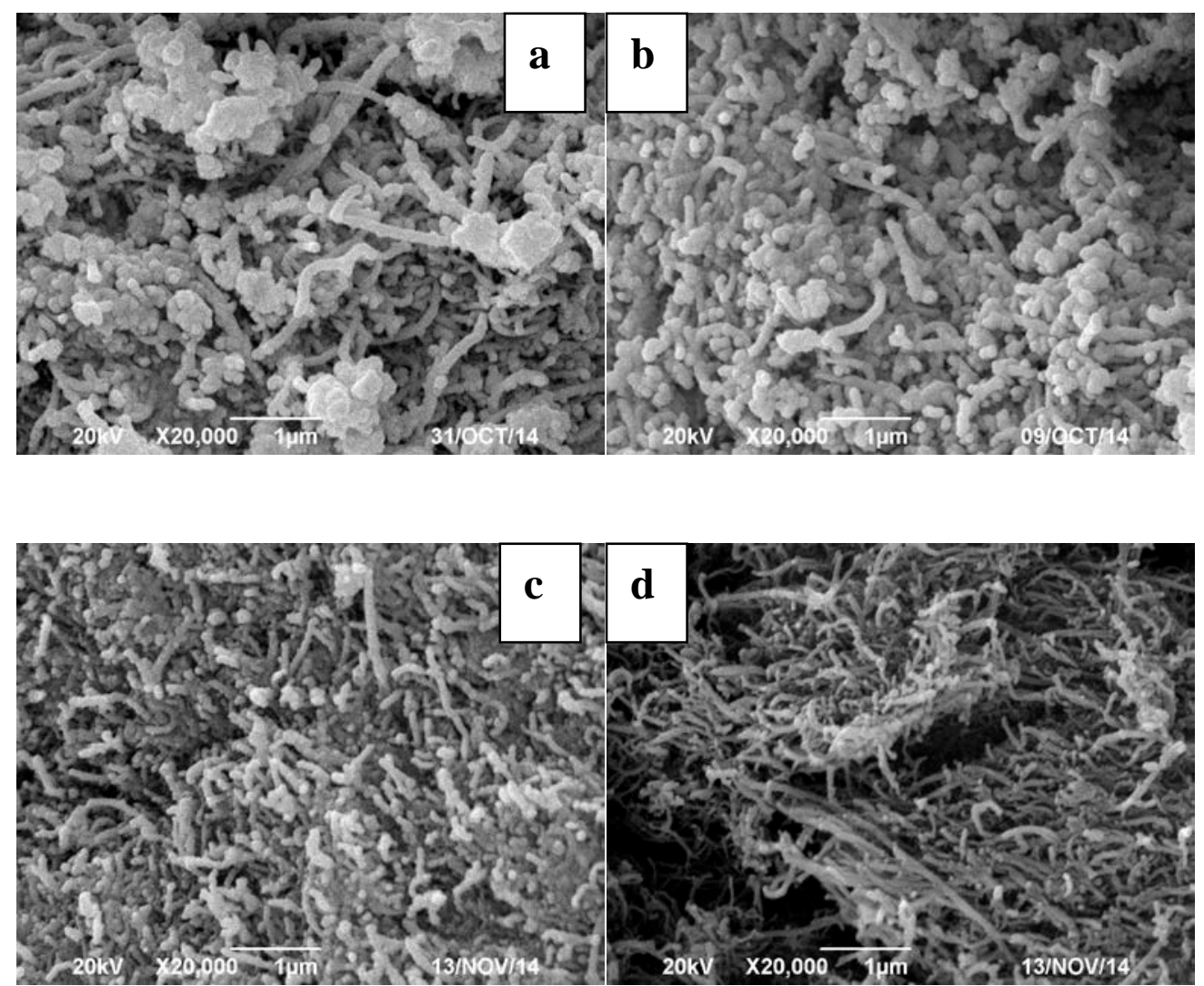

Fig. 2 The SEM image of $\mathrm{TiO}_{2} / \mathrm{CNTs}$ prepared at various $\mathrm{pH}, 3.0(\mathrm{a}), 6.3(\mathrm{~b}), 9.8$ (c), 12.1(d)

\subsection{Specific surface area characteristics of TiO2/ CNTs}

Fig.3 depicts nitrogen adsorption-desorption isothermal curves and pore size distribution of TiO2/CNTs. It can be seen clearly all isotherms are type IV curves, confirming their mesoporous character. The sharp increase of sorption at $\mathrm{P} / \mathrm{P} 0>0.8$ is mainly attributed to nitrogen condensation between the entangled nanotubes and to a lesser extent in the central canal of the nanotubes with open tips, in accordance to Jurewicz's report [19]. The total surface area of TiO2/CNTs was measured to be $159.2 \mathrm{~m} 2 / \mathrm{g}$.

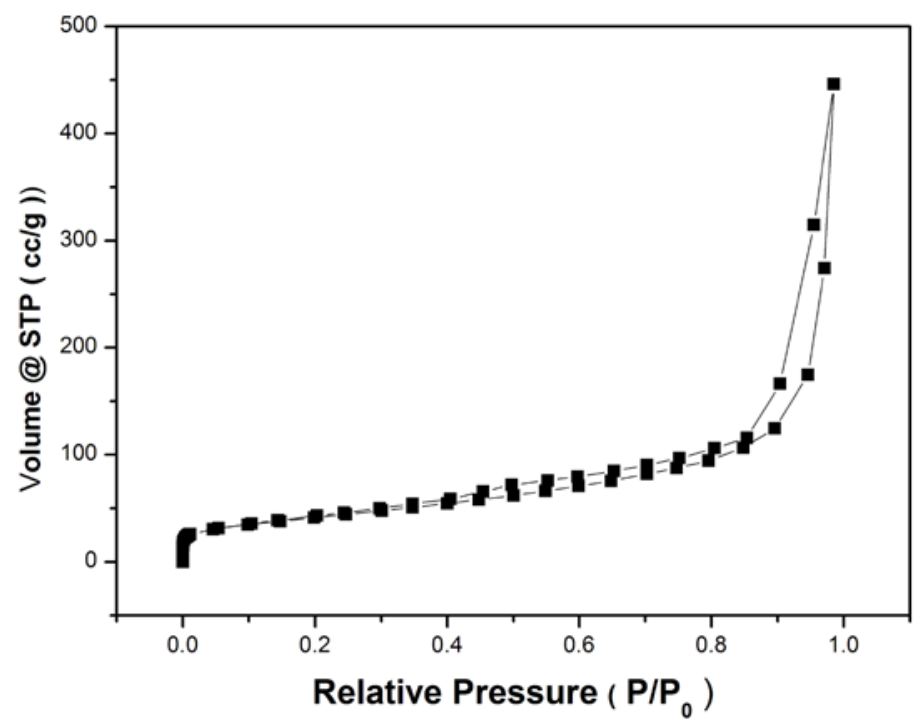

Fig. 5. Nitrogen adsorption-desorption isothermal curves of the sample.

\subsection{Adsorptive characteristics of $\mathrm{TiO} 2 / \mathrm{CNTs}$ for $\mathbf{P b}$}

Fig. 4 shows the influence of $\mathrm{pH}$ of test solution on the adsorption of $\mathrm{Pb} 2+$ by TiO2/CNTs at $\mathrm{pH}$ 2.8-11.3. As it is seen, there are significant increases in removal efficiency with increasing $\mathrm{pH}$ values. At $\mathrm{pH}$ 2.8-4, the removal efficiency was low. It was probably TiO2/CNTs surface groups 
adsorb $\mathrm{H}+$, which competed with $\mathrm{Pb} 2+$. The significant enhancement in removal efficiency with increasing $\mathrm{pH}$ values from 7.9 to11.3 is most probably due to formatiom $\mathrm{Pb}(\mathrm{OH}) 2$.Hence, at pH5.1-6.2, it exhibited actually removal efficiency of TiO2/CNTs. The removal efficiency was $83.2 \%$.

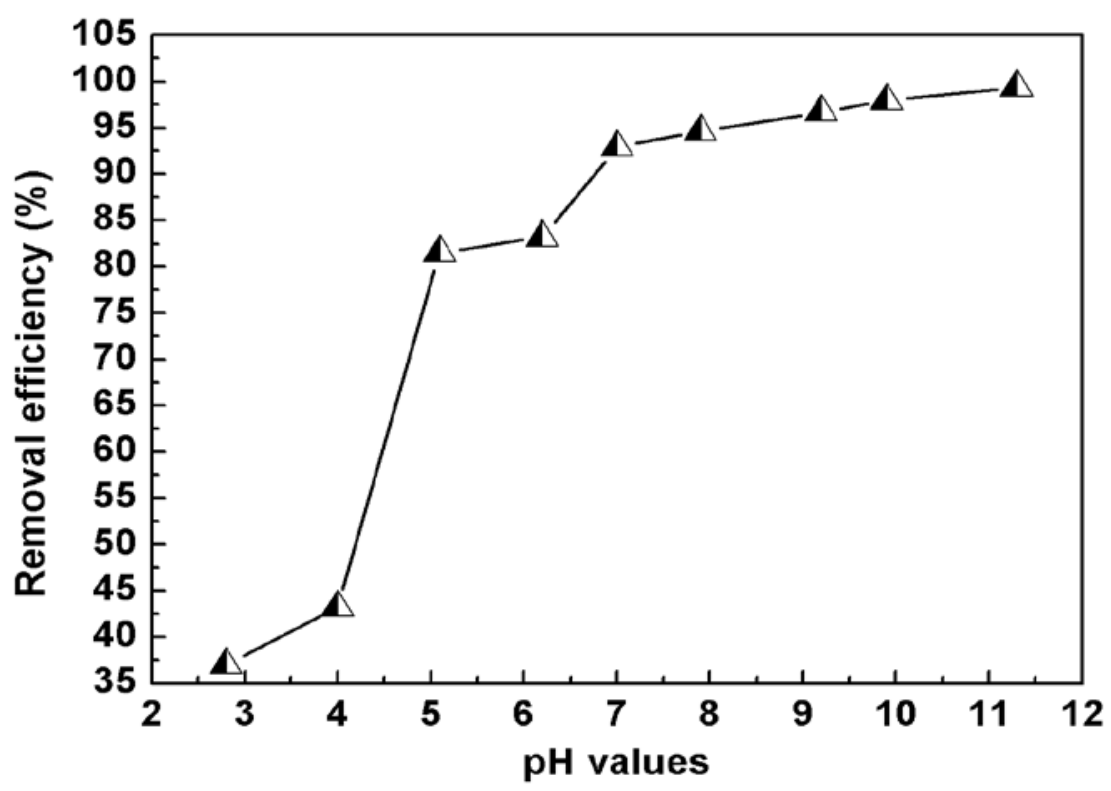

Fig. $4 \mathrm{pH}$ values efffect on removal efficiency

\section{Conclusions}

In summary, a facile process has been successfully employed to prepare TiO2/CNTs. The hydrothermal temperature influenced eminently $\mathrm{TiO} 2$ crystallation. The solution $\mathrm{pH}$ influenced TiO2 loading amount. TiO2/CNTs displayed high removal efficiency for $\mathrm{Pb} 2+$.

\section{Acknowledgements}

This work was funded by the special S\&T project on treatment and control of water pollution (2010ZX07212-008), science and technology plan of Changsha Municipal Science and Technology bureau (k1303001-11), innovation fund of Changsha Research Institute of Mining and Metallurgy(2013-102A).

\section{Refences}

1. Bonato, M.; Ragnarsdottir, K.; Allen, G., Removal of uranium (VI), lead (II) at the surface of $\mathrm{TiO}_{2}$ nanotubes studied by X-ray photoelectron spectroscopy. Water, Air, \& Soil Pollution, 223, (7), pp.3845-3857, 2012.

2. Djedidi, Z.; Bouda, M.; Souissi, M. A.; Cheikh, R. B.; Mercier, G.; Tyagi, R. D.; Blais, J.-F., Metals removal from soil, fly ash and sewage sludge leachates by precipitation and dewatering properties of the generated sludge. Journal of Hazardous Materials, 172, (2-3), pp.1372-1382, 2009.

3. O’Connell, D. W.; Birkinshaw, C.; O’Dwyer, T. F., Heavy metal adsorbents prepared from the modification of cellulose: A review. Bioresource Technology, 99, (15), pp.6709-6724, 2008.

4. Yi, G.; Lu, H.; Zhao, S.; Ge, Y.; Yang, W.; Chen, D.; Guo, L.-H., Synthesis, characterization, and biological application of size-controlled nanocrystalline NaYF4: Yb, Er infrared-to-visible up-conversion phosphors. Nano Letters, 4, (11), pp.2191-2196, 2004.

5. Carreño, G.; Sosa, E.; González, I.; Ponce-de-León, C.; Batina, N.; Oropeza, M., Anion influence in lead removal from aqueous solution by deposition onto a vitreous carbon electrode. Electrochimica acta, 44, (15), pp.2633-2643, 1999.

6. Lounici, H.; Addour, L.; Belhocine, D.; Grib, H.; Nicolas, S.; Bariou, B.; Mameri, N., Study of 
a new technique for fluoride removal from water. Desalination, 114, (3), pp.241-251, 1997.

7. Lu, G.; Ocola, L. E.; Chen, J., Room-Temperature Gas Sensing Based on Electron Transfer between Discrete Tin Oxide Nanocrystals and Multiwalled Carbon Nanotubes. Advanced Materials, 21, (24), pp.2487-2491, 2009.

8. Tian, P.; Han, X.-y.; Ning, G.-l.; Fang, H.-X.; Ye, J.-w.; Gong, W.-t.; Lin, Y., Synthesis of Porous Hierarchical MgO and Its Superb Adsorption Properties. ACS applied materials \& interfaces, 5, (23), pp.12411-12418, 2013.

9. Hoffmann, M. R.; Martin, S. T.; Choi, W.; Bahnemann, D. W., Environmental applications of semiconductor photocatalysis. Chemical reviews, 95, (1), pp.69-96, 1995.

10. Peng, J.-f.; Song, Y.-h.; Yuan, P.; Cui, X.-y.; Qiu, G.-l., The remediation of heavy metals contaminated sediment. Journal of Hazardous Materials, 161, (2-3), pp.633-640, 2009.

11. Tang, W.; Li, Q.; Li, C.; Gao, S.; Shang, J. K., Ultrafine $\alpha-\mathrm{Fe}_{2} \mathrm{O}_{3}$ nanoparticles grown in confinement of in situ self-formed "cage" and their superior adsorption performance on arsenic (III). Journal of Nanoparticle Research, 13, (6), pp.2641-2651, 2011.

12. Thompson, T. L.; Yates Jr, J. T., $\mathrm{TiO}_{2}$-based photocatalysis: Surface defects, oxygen and charge transfer. Topics in Catalysis, 35, (3-4), pp.197-210, 2005.

13. Fujishima, A.; Honda, $\mathrm{K} ., \mathrm{TiO}_{2}$ photoelectrochemistry and photocatalysis. Nature, 238, (5358), pp.37-38, 1972.

14. Fujishima, A.; Rao, T. N.; Tryk, D. A., Titanium dioxide photocatalysis. Journal of Photochemistry and Photobiology C: Photochemistry Reviews, 1, (1), pp.1-21, 2000.

15. Luo, T.; Cui, J.; Hu, S.; Huang, Y.; Jing, C., Arsenic removal and recovery from copper smelting wastewater using $\mathrm{TiO}_{2}$. Environmental science \& technology, 44, (23), pp.9094-9098, 2010.

16. Shi, K.; Wang, X.; Guo, Z.; Wang, S.; Wu, W., Se (IV) sorption on $\mathrm{TiO}_{2}$ : Sorption kinetics and surface complexation modeling. Colloids and Surfaces A: Physicochemical and Engineering Aspects, 349, (1), pp.90-95, 2009.

17. Correa-Duarte, M. A.; Wagner, N.; Rojas-Chapana, J.; Morsczeck, C.; Thie, M.; Giersig, M., Fabrication and biocompatibility of carbon nanotube-based 3D networks as scaffolds for cell seeding and growth. Nano Letters, 4, (11), pp.2233-2236, 2004.

18. Dang, L.; Zhang, G.; Kan, K.; Lin, Y.; Bai, F.; Shen, P.; Li, L.; Shi, K., Heterostructured $\mathrm{Co}_{3} \mathrm{O}_{4}$ /PEI-CNTs composite: fabrication, characterization and $\mathrm{CO}$ gas sensors at room temperature. Journal of Materials Chemistry A, 2, (13), pp.4558-4565, 2014.

19. Jurewicz, K.; Babeł, K.; Pietrzak, R.; Delpeux, S.; Wachowska, H., Capacitance properties of multi-walled carbon nanotubes modified by activation and ammoxidation. Carbon, 44, (12), pp.2368-2375, 2006. 